\title{
Does the frequency of routine follow-up after curative treatment for head-and-neck cancer affect survival?
}

\author{
S.F. Hall MSc $\mathrm{MD}^{*}{ }^{*}$ T. Owen $\mathrm{MD}^{\dagger}{ }^{\dagger}$ R.J. Griffiths $\mathrm{BSc}^{\ddagger}$ and K. Brennan $\mathrm{MSc}^{\S}$
}

\begin{abstract}
Background Routine follow-up is a cornerstone of oncology practice, but evidence to support most aspects of followup is lacking. Our objective was to investigate the relationship between frequency of routine follow-up and survival.

Methods This population-based study used electronic health care data relating to 5310 patients from Ontario diagnosed with squamous-cell head-and-neck cancer during 2007-2012. Treatments included surgery (24.6\%), radiotherapy with or without chemotherapy (52.4\%), and combined surgery and radiotherapy (23\%). We determined the oncologist who was following each patient after treatment; calculated the average follow-up visits to the oncologist during the subsequent 2.5 years for all patients who were doing well; and used Kaplan-Meier and multiple variable regression analysis to compare, by treatment, overall survival for patients in the high, typical, and low follow-up oncologist groups.
\end{abstract}

Results Many oncologists saw patients $40 \%-80 \%$ more often than other oncologists did. No relationship of appointment frequency with survival was observed for patients in any treatment group.

Conclusions The practice of routine follow-up varies and is costly both to a health care system and to patients. Without evidence about the effectiveness of current policies, further research is required to investigate new or optimal practices.

Key Words Head-and-neck cancer, routine follow-up, follow-up frequency, disease surveillance, populationbased research

www.current-oncology.com

\section{INTRODUCTION}

The greatest challenge of the large and growing prevalence of cancer survivors is how best to provide long term follow-up care.

- Dr. Eva Grunfeld ${ }^{1}$

Routine follow-up after curative cancer treatment is a time-honoured, yet resource-intensive practice that is expensive for patients, physicians, and the health care system providing both tumour surveillance and patient survivorship care. Numerous organizations have published consensus-based guidelines for routine follow-up in patients with head-and-neck cancer (HNC) ${ }^{2-6}$, but in the absence of evidence-comparing guidelines or even the effectiveness of routine follow-up itself ${ }^{6-14}$, research into optimal policies is needed ${ }^{15-17}$. And that need is particularly relevant given the increasing number of patients with $\mathrm{HNC}^{18,19}$ and the excellent survival in patients with disease related to the human papillomavirus.

"When there is no evidence, practice will vary" 20 . In a previously reported study based on 3675 patients, we assessed the variation in HNC follow-up in Ontario ${ }^{21}$. We found marked variation in all aspects of follow-up (including frequency of appointments), without substantial relationship to guidelines. The objective of the present study was to compare survival outcomes for patients receiving routine follow-up after curative treatment across groups of oncologists with different follow-up practices or philosophies. The universal publicly funded health care in the province 
of Ontario, the legislated collection of health records, and the availability of relevant datasets at ICES allow for unique studies of complete, unselected patient populations.

\section{METHODS}

\section{Study Design and Setting}

This retrospective population-based study from Ontario analyzed the outcomes of patients who were followed by oncologists with different follow-up practices. Each patient was assigned to a single follow-up oncologist, and the mean frequency of routine follow-up visits by the patients assigned to the oncologist was determined. Follow-up practice was then divided into low, typical, and high routine follow-up frequency (RFF) groups, and the outcomes of the RFF groups were compared. In Ontario, all patients with complex HNC are treated at 1 of 8 regional HNC treatment centres (including Princess Margaret Hospital), which are located at major teaching hospitals. The hospitals and cancer centres are staffed by experienced surgical, radiation, and medical oncologists, and all patients are reviewed at multidisciplinary tumour boards. Ontario has a population of more than 13 million people.

\section{Dataset Creation}

The independent, nonprofit research organization ICEs is funded by the Ontario Ministry of Health and Long-Term Care and manages electronic data holdings that include all health care-related events for the entire population of Ontario, linked using an anonymous unique identifier for each person. To protect the privacy of personal health information, values involving 5 or fewer people cannot be reported.

\section{Data Sources}

The Ontario Cancer Registry (OCR) is a population-based cancer registry that captures information on all incident cases of cancer in Ontario. It is based on Ontario pathology reports abstracted at the ocR, electronic records submitted from the regional cancer centres, hospital discharge records, and reports of death from the Registrar General of Ontario. The ocR also contains patient demographics, date of diagnosis, and vital status.

The oHIP (Ontario Health Insurance Plan) database contains data about all fee-for-service claims submitted by, and paid to, physicians.

The Ontario Registered Persons Database provides demographic information about all residents of Ontario who are eligible for OHIP.

The Ontario Registrar General provides vital status and cause of death for all residents of Ontario.

The Discharge Abstract Database maintained by the Canadian Institute for Health Information (CIHI) contains information about all hospital discharges, including surgery.

The Activity Level Reporting (ALR) file is the common electronic patient treatment database used by all Ontario cancer centres and Princess Margaret Hospital. The data held in the ALR include Radiation Planning/Treatment Activity records and Systemic Drug Delivery Event records. For the present work, the ALR provided radiotherapy (RT) data (intent, dose, frequency, and dates) and chemotherapy data.

\section{Study Population}

All patients 35-75 years of age with a new diagnosis of squamous cell carcinoma of the head and neck (oral cavity, oropharynx, nasopharynx, larynx, hypopharynx) between 1 January 2007 and 31 December 2012 were identified based on International Classification of Diseases codes in the ocr $(n=7890)$. Patients were excluded if they previously had a diagnosis of HNC or if they developed another cancer (total: 1004, including 380 with prior HNC and 130 with gastrointestinal, 239 with lung, 17 with breast, 48 with thyroid, and 42 with prostate malignancies) during the follow-up period because those individuals would have different follow-up patterns. Also excluded were people receiving palliative, no, or undetermined treatment $(n=1314)$ or lacking continuous health care coverage, leaving 5310 patients for the analysis. Follow-up data were available until 31 December 2016.

\section{Variables}

Comorbidity was established using the Elixhauser Comorbidity Index ${ }^{22-24}$, which was designed for research using administrative data. The index is based on a 5-year lookback window of hospitalizations. It is a summative scale that considers 31 domains, and we used cut-points of 0,1 , 2 , and more than $2^{25,26}$, with greater comorbidity resulting in higher scores.

\section{Extent of Disease}

In the ocR dataset, TNM categories and stage groups were not reliably available for patients with HNC during the period of interest ${ }^{26}$. We created a surrogate for extent of disease based on surgical billing codes for total resection (T3-4), partial resection (T1-2), and neck dissection (N0 or $\mathrm{N}+$ ) to create 3 groups: early, early $\mathrm{N}+$, and advanced (Table I).

Vital status and cause of death were determined from the Ontario Registrar General and the Ontario Registered Persons Database to 31 December 2016.

\section{Treatment}

Treatment was determined using data from the ALR and multiple files maintained by онIP and cinı. Surgical procedures were identified using Canadian Classification of Health Interventions codes that were obtained from hospital discharge data and then linked, based on dates, to the оHIP surgical billing data to identify the associated surgical oncologist (Table I). Treatment was assigned to patients based on the assumption that curative treatment would occur within 4 months of the date of diagnosis. "Initial treatment" included salvage treatment if it occurred within 4 months of the first treatment completion. Recurrence was defined as another or subsequent treatment more than 4 months after completion of the initial curative treatment. Neck dissection before RT or chemoradiotherapy was considered to be part of primary treatment. For the purposes of the present study, patients were assigned to 1 of 4 treatment groups:

\section{Primary surgery}

Surgery was defined as non-biopsy surgery within 4 months of diagnosis. For patients with glottis cancer, biopsy was considered treatment (of early-stage disease) if it was the only billed treatment event. 
Primary RT with or without chemotherapy

The definition of RT was 20 or more fractions and 5000 cGy or more within 4 months of diagnosis. Any RT treatment involving fewer than 20 fractions or less

TABLE I Patient and treatment variables for the 3071 patients in the study population

\begin{tabular}{lc}
\hline \multicolumn{1}{c}{ Variable } & $\begin{array}{c}\text { Value } \\
{[\boldsymbol{n}(\%)]}\end{array}$ \\
\hline Sex & \\
Women & $740(24.1)$ \\
Men & $2331(75.9)$ \\
Age group & \\
35-45 Years & $205(6.7)$ \\
$46-55$ Years & $875(28.5)$ \\
$56-65$ Years & $1173(38.2)$ \\
$66-75$ Years & $818(26.6)$ \\
Comorbidity group ${ }^{\mathrm{a}}$ & \\
0 & $2216(72.2)$ \\
1 & $507(16.5)$ \\
2 & $174(5.7)$ \\
$\geq 3$ & $174(5.7)$ \\
Extent of disease & \\
Early & $2040(66.4)$ \\
Marly N+ & $254(8.3)$ \\
\hline & $777(25.3)$ \\
& 1720 \\
\hline
\end{tabular}

Site

$\begin{array}{lc}\text { Hypopharynx } & 180(5.9) \\ \text { Larynx } & 751(24.5) \\ \text { Nasopharynx } & 108(3.5) \\ \text { Oral cavity } & 1347(43.9) \\ \text { Oropharynx } & 685(22.3)\end{array}$

$\begin{array}{lcc}\text { Treatment } \\ \text { Surgery (Sx) } & & \\ \text { Radiotherapy (RT) } & \text { RT } & 672(21.9) \\ & \text { ICRT } & 52(1.7) \\ & \text { RT+/- CT } & 885(28.8) \\ \text { Combined treatment } & \text { SX PLUS RT } & 404(13.2) \\ & \text { SX plus CRT } & 176(5.7) \\ & \text { CRT plus Sx } & 94(3.1) \\ & \text { RT plus Sx } & 24(0.8) \\ & \text { other } & 7(0.2)\end{array}$

Score on Elixhauser Comorbidity index.

ICRT = induction chemoradiotherapy, CT = chemotherapy, RT = Radiotherapy, CRT = chemoradiotherapy. than 5000 cGy was deemed palliative. For the present study, the RT group included patients receiving concomitant chemoradiotherapy based on a record of chemotherapy that started up to 30 days before the first day of RT or no later than RT completion. Induction chemotherapy with RT was defined as chemotherapy beginning within 4 months of diagnosis and more than 30 days before or ending before the start of RT.

\section{Surgery plus $R T$}

Combined treatment included RT after surgery or surgery after RT within 4 months of initial treatment completion, on the assumption that such treatments would be given for residual disease, positive margins, or planned combined treatment. This group also included patients who received concomitant or induction chemotherapy and surgery.

\section{No treatment}

This group included patients receiving palliative treatment (any treatment delivered more than 4 months after diagnosis, RT using fewer than 20 fractions or less than $5000 \mathrm{cGy}$, or chemotherapy alone), those with incomplete data (for whom treatments could not be determined), or those undergoing biopsy alone (that is, no treatment). Patients in this group were excluded from the analysis.

\section{Index Follow-Up Oncologist}

Our objective was to assign patients to the oncologist who was making the decisions concerning their routine follow-up. Patients were initially assigned to the surgical oncologist who performed the most extensive procedure or to the radiation oncologist who planned their RT. For any patient, the follow-up oncologist within multidisciplinary clinics can change after complex multimodality treatments or after staff changes, and because of those factors, we assigned the remaining patients to the surgical or radiation oncologist who saw them the most. For patients receiving combined treatment, we used the surgical or radiation oncologist who saw them the most, and if the number of visits resulted in a tie, the patient was assigned to the radiation oncologist. After treatment completion, medical oncologists rarely saw patients more than once and therefore were not included in the analysis.

For each patient, we determined the total number of follow-up appointments in the 2.5 years covering the period from 6 months to 3 years after completion of treatment. We chose total appointments to blend any differences in follow-up over the 2.5 years and to capture all appointments. When calculating the total number of follow-up visits, multiple appointments for the same patient on the same day were counted as a single appointment; however, to determine which physician saw the patient the most, each visit was taken into account. We matched $66.3 \%$ of the patients with the treating oncologist and $33.7 \%$ with the oncologist who did the most follow-up (if that individual was not the treating oncologist).

\section{RFF Groups}

Our objective was to assign a mean to the frequency of total routine follow-up appointments across all the well patients 
of each radiation and surgical oncologist so as to classify them into a low, typical, or high RFF group. Appointment rates for patients who developed recurrence would be different before and after recurrence, and those patients were therefore excluded ( $n=2248)$ for the creation of the RFF groups. Patients with no oncologist follow-up record were also excluded, leaving 2958 patients for the creation of the RFF groups. The average total appointments for the 2.5 years beginning 6 months after completion of treatment for each index oncologist was calculated. The range of the means across the radiation and surgical oncologists was then divided into 3 equal groups ("bins") to create low-, typical-, and high-frequency follow-up groups (RFF groups). Each oncologist was then assigned to a bin. Unlike tertiles, which are based on a frequency distribution, the bin method creates groups of equal size. All the patients belonging to each radiation oncologist and each surgical oncologist went into the bin that matched their oncologist's appointment frequency. Based on the resulting patient cohorts, oncologists were excluded if they saw fewer than 10 patients, leaving 20 surgical and 31 radiation oncologists in 8 Ontario regional cancer treatment centres for the analysis. We did not adjust for new oncologists or exclude retiring oncologists who were working for only part of the study period. The mean numbers of follow-up appointments in the 3 RFF groups were compared using analysis of variance in conjunction with the Tukey test.

\section{Analysis}

Our objective was to compare outcomes by RFF group based on well patients receiving routine follow-up in each group. Patients with a poor prognosis were excluded (those who died within 1 year, and those who recurred within 4 months of the end of treatment, $n=1021$ ), because they would have additional appointments. Patients with no follow-up and patients of excluded oncologists $(n=1084)$ were also excluded, leaving 3071 patients for the final comparisons. The outcomes by RFF group were compared based on treatment group (surgery, RT with or without chemotherapy, surgery plus RT). We report overall survival (os) and disease-specific survival (Dss) using Kaplan-Meier curves with log-rank tests and multivariable analysis (Cox proportional hazards regression models) controlling for age (35-45 years), sex (female), comorbidity (none), site (oral cavity), extent of disease (early), and RFF group (high).

\section{RESULTS}

Table I presents patient, tumour, and treatment variables for the full study population of 5017 patients $(76 \%$ men, $72 \%$ with no significant comorbidity, and oral cavity as the most common site). Primary treatment was surgery in $24.6 \%$ of the patients; in $52.4 \%$, it was RT with or without chemotherapy, and in $23 \%$, it was surgery plus RT (combined treatment). A value for the "extent of disease" variable was missing when the patient had been treated with RT (with or without chemotherapy), because no surgical codes were available.

Table II presents the mean number of visits and the range of visits for each of the RFF groups by treatment group. The patients receiving RT with or without chemotherapy had the widest range of visits. As expected, the mean number of visits was greatest for the surgery plus RT groups and lowest for 2 of the 3 surgery groups. All RFF groups were statistically significantly different based on analysis of variance $(p<0.05)$. By treatment received, the patients of the oncologists in the highest RFF group, compared with the patients of the oncologists in the lowest RFF group, were seen $45 \%$ (surgery), $82 \%$ (RT with or without chemotherapy), and $40 \%$ (surgery plus RT) more often.

Table III represents patient, tumour, and treatment variables for the surgery plus RT group by RFF group. No differences in patient age, sex, or comorbidity were evident between the RFF groups, but differences in site and extent of disease were observed-that is, more patients with more advanced disease had more visits, as expected. In the surgery group, patients with more comorbidity and greater extent of disease were seen more often (Table IV). In the RT group, patients with a longer treatment time were seen more often, and patients who received chemotherapy were seen less often (Table v).

Figure 1(A-C) presents the Kaplan-Meier curves for os by RFF group for the surgery, RT with or without chemotherapy, and surgery plus RT groups. No statistically significant difference between the groups were evident for any of the treatments $(\log$-rank $p=0.146,0.155$, and 0.379 respectively). Similar results were obtained for Dss (logrank $p=0.547,0.744$, and 0.886 respectively).

Table vi presents the results of the Cox proportional hazards models for os for the surgery group. No effect of RFF group was evident. The factors that predicted poor outcome were a comorbidity score greater than 1 and the hypopharynx as the tumour site. Similarly, RFF group was not associated with os or Dss in patients treated with RT with or without chemotherapy or in those treated with surgery plus RT (Table VII). When the models were run without the extent-of-disease variable, little change in the hazard ratios for os and Dss and no change in statistical significance was observed (data not shown).

\section{DISCUSSION}

The objective of the present study was to compare the survival outcomes of well patients returning for routine follow-up appointments, anchored on known variation in follow-up frequency. We created groups of low, typical, and high follow-up oncologists (RFF groups) and compared outcomes of patients following using those different approaches. The patient group consisted of 3071 real-world patients diagnosed in Ontario between 1 January 2007 and 31 December 2012. Many oncologists saw patients $40 \%-80 \%$ more often than their colleagues did; however, no relationship between follow-up frequency and survival was observed regardless of whether patients had been treated with surgery, RT with or without chemotherapy, or combined surgery and RT.

The practice of routine follow-up includes assessment of treatment morbidity, examination for second cancers, emotional support, and reassurance. Although further research is required to assess the effectiveness of routine follow-up for those outcomes, the most important outcome for patients, especially in the first few years, 
TABLE II The distributions of the patient and tumour variables by routine follow-up frequency group for the surgery group

\begin{tabular}{|c|c|c|c|c|c|c|}
\hline \multirow{3}{*}{$\begin{array}{c}\text { RFF } \\
\text { group }\end{array}$} & \multicolumn{6}{|c|}{ Treatment group } \\
\hline & \multicolumn{2}{|c|}{ Surgery } & \multicolumn{2}{|c|}{ Radiotherapy } & \multicolumn{2}{|c|}{ Combined } \\
\hline & Mean & Range & Mean & Range & Mean & Range \\
\hline Low & 5.84 & 5.28 to $<6.46$ & 5.75 & 3.64 to $<6.49$ & 7.90 & 7.0 to $<8.75$ \\
\hline Typical & 6.93 & 6.46 to $<7.63$ & 8.24 & 6.4 to $<9.34$ & 9.48 & 8.75 to $<10.5$ \\
\hline High & 8.46 & 7.63 to 8.80 & 10.50 & 9.34 to 12.18 & 11.08 & 10.5 to 12.25 \\
\hline
\end{tabular}

is survival. Routine follow-up is essential, but how it is performed and how to make it both efficient and effective needs further investigation.

Consensus-based guidelines proposed by various organizations have specified appointment frequency grids based on years after treatment completion; however, there is no evidence that the grids themselves lead to better outcomes $^{6-17}$. Reviews and practice surveys of grids, schedules, and guidelines conclude "At present several guidelines are available, there is insufficient evidence to recommend one guideline to others" 27 and "well controlled studies demonstrating the superiority of any specific followup strategy over alternative strategies [are absent]" ${ }^{28}$. In the absence of evidence, authors including Boysen et al ${ }^{15}$, Flynn et al. ${ }^{16}$, and Lester and Wight ${ }^{17}$ proposed alternatives, including symptom-based follow-up appointments plus patient education. In a Canadian study, Flynn et al. ${ }^{16}$ reported that "the recurrences detected on routine surveillance did not result in better salvage rates or survival in comparison with the symptom-based recurrence group ... and concluded that there is little added value to regular surveillance for the intent of improving disease control and/or survival." Lester and Wight ${ }^{17}$ concluded, based on their study of 676 patients, that "[they] were over-monitoring patients ... and that further work is required to evaluate whether a routine schedule is the most effective way to deliver follow-up care."

The most recent consensus-based guideline ${ }^{29}$ states "Unfortunately, the lack of available evidence continues to challenge clinicians in making practice decisions for HNC survivors" and suggests a flexible grid. Using that grid, the patients in our study would have had 5.5-15 appointments during the 2.5-year study timeframe, and almost all of them would have fit into that range. Interestingly, in the current climate of patient-centred care and personalized care, the literature contains minimal discussion about what patients want or expect from the routine follow-up suggested in any of the guideline documents when the patients are the ones who bear the travel and emotional costs of the visits ${ }^{30}$.

The strengths of the present study include its complete unselected dataset and a unique method that compared differences in physician philosophy and the outcomes of appropriate patients rather than using grids and timetables based on all patients. There are also potential limitations.

The first potential limitation is the selection bias of our cohort for the survival analysis. The RFF groups created to establish each oncologist's routine follow-up pattern were based on well patients and therefore those patients, their tumour factors, and their treatments do not reflect the overall population of a head-and-neck clinic. Furthermore, the RFF groups were tested based on patients who survived 1 year or did not quickly recur, because those patients would have required more follow-up and would have skewed the outcomes. However, it is unlikely that our selection process would have altered the results because the selected patients are part of the case mix of all oncologists and the follow-up of sicker patients was not our question.

The second potential limitation is that we do not have data on extent of disease (stage) because neither TNM nor stage groups were reliably recorded in electronic format during our study period ${ }^{26}$. In the absence of stage data, we used an imperfect surrogate based on total compared with partial resection and use (or not) of neck dissection to classify surgical patients into early, early $\mathrm{N}+$, and advanced for the surgery and surgery plus RT groups. That surrogate could not be applied to the analyses of the RT group. The surrogate also has flaws such as assigning $\mathrm{N}+$ to a patient with pathologically negative neck nodes after neck dissection; however, we have no data source that recognizes the latter situation, the number of those patients is small, and all surgeons are going to have such patients in their case mix. Furthermore, the analysis did not change when extent of disease was removed from the Cox models, suggesting that extent of disease was not driving survival in the follow-up groups.

The third potential limitation is that some surgeons and radiation oncologists might have had different patient profiles because of factors such as expertise and referral patterns that could influence their follow-up policies. However, the assignment of each oncologist to a RFF group was based on all their patients, and given that cancer care is regionalized across Ontario, the case mix for all oncologists includes patients with typical sites, extents of disease, and comorbidities.

The fourth potential limitation is our assignment of recurrence. Recurrence was defined as another or subsequent treatment after completion of the initial treatment, 4 months or more after curative treatment. Unfortunately, neither the ocR nor the CIHI databases have a reliable mechanism to identify recurrence, and in the absence of pathology reports for the subsequent treatments, it is possible that some patients have been wrongly labelled as recurrent. An example is a patient undergoing neck dissection 6 months after RT for a persistent mass that results in a finding of "benign." Such situations are uncommon and part of the practices of all oncologists; in the absence of more complete data, no other definition of recurrence was possible. 
TABLE III The distributions of the patient and tumour variables by Routine Frequency of Follow-up Group (RRF) for the Combined Treatment (Surgery and Radiotherapy +/- Chemotherapy) patients

\begin{tabular}{lcccc}
\hline \multirow{2}{*}{ Variable } & \multicolumn{3}{c}{ RFF group [n(\%)] } & $\begin{array}{c}\boldsymbol{p} \\
\text { Value }\end{array}$ \\
\cline { 2 - 4 } & Low & Typical & High & \\
\hline Patients $(n)$ & 293 & 230 & 71 & \\
Sex & & & & \\
Women & $60(20.5)$ & $50(21.7)$ & $19(26.8)$ & 0.515 \\
Men & $233(79.5)$ & $180(78.3)$ & $52(73.2)$ &
\end{tabular}

Age group

$\begin{array}{ccccc}\text { 35-45 Years } & 17(5.8) & 19(8.3) & \leq 10 & 0.432 \\ \text { 46-55 Years } & 82(28.0) & 50(21.7) & 22(31.0) & \\ \text { 56-65 Years } & 107(36.5) & 97(42.2) & 26(36.6) & \\ \text { 66-75 Years } & 87(29.7) & 64(27.8) & \leq 20 & \\ \text { Comorbidity group a } & & & & \\ 0 & 212(72.4) & 163(70.9) & 50(70.4) & 0.968 \\ 1 & 44(15.0) & 36(15.7) & 9(12.7) & \\ 2 & 20(6.8) & 15(6.5) & 6(8.5) & \\ \geq 3 & 17(5.8) & 16(7.0) & 6(8.5) & \end{array}$

Site

$\begin{array}{lcccc}\text { Hypopharynx } & 18(6.1) & 10(4.3) & \leq 10 & <0.001 \\ \text { Larynx } & 118(40.3) & 77(33.5) & 27(38.0) & \\ \text { Oral cavity } & 118(40.3) & 131(57.0) & 33(46.5) \\ \text { Oropharynx } & 39(13.3) & 12(5.2) & \leq 10\end{array}$

$\begin{array}{lcccc}\text { Oropharynx } & 39(13.3) & 12(5.2) & \leq 10 & \\ \text { Extent of disease } & & & & \\ \text { Early } & 165(56.3) & 74(32.2) & \leq 15 & <0.001 \\ \text { Early N+ } & 12(4.1) & 12(5.2) & \leq 10 & \\ \text { Advanced } & 116(39.6) & 144(62.6) & 53(74.6)\end{array}$

Extent of surgery

$\begin{array}{ccccc}\text { Partial } & 177(60.4) & 86(37.4) & 18(25.4) & <0.001 \\ \text { Total } & 116(39.6) & 144(62.6) & 53(74.6) & \\ \text { Neck dissection } & & & & \\ \text { No } & 181(61.8) & 84(36.5) & 18(25.4) & <0.001 \\ \text { Yes } & 112(38.2) & 146(63.5) & 53(74.6) & \end{array}$

Chemotherapy

\begin{tabular}{lcccc} 
No & $197(67.2)$ & $166(72.2)$ & $45(63.4)$ & 0.284 \\
Yes & $96(32.8)$ & $64(27.8)$ & $26(36.6)$ & \\
Total & 293 & 230 & 71 \\
\hline
\end{tabular}

a Score on the Elixhauser Comorbidity Index.

The fifth potential limitation is that we have not included the outcomes of second primaries. The development of second primaries is a major problem in head-and-neck oncology; however, in the absence of evidence about the effectiveness of screening for second primaries and about who should screen patients, when patients should be
TABLE IV The distributions of the patient and tumour variables by RFF group for the Surgery patients ${ }^{\mathrm{a}}$

\begin{tabular}{lcccc}
\hline \multirow{2}{*}{ Variable } & \multicolumn{3}{c}{ Follow-up } & $\begin{array}{c}p \\
\text { Value }\end{array}$ \\
\cline { 2 - 4 } & Low & Typical & High \\
\hline Patients (n) & 244 & 302 & 211 & \\
Sex [n (\%)] & & & & \\
Women & $96(39.3)$ & $119(39.4)$ & $67(31.8)$ & 0.151 \\
Men & $148(60.7)$ & $183(60.6)$ & $144(68.2)$ &
\end{tabular}

Age group

$\begin{array}{ccccc}35-45 \text { Years } & 23(9.4) & 22(7.3) & 20(9.5) & 0.49 \\ \text { 46-55 Years } & 57(23.4) & 73(24.2) & 53(25.1) & \\ \text { 56-65 Years } & 81(33.2) & 91(30.1) & 76(36.0) \\ 66-75 \text { Years } & 83(34.0) & 116(38.4) & 62(29.4)\end{array}$

Comorbidity group ${ }^{b}$

\begin{tabular}{|c|c|c|c|}
\hline 0 & $188(77.0)$ & $221(73.2)$ & $166(78.7)$ \\
\hline 1 & $41(16.8)$ & $44(14.6)$ & $20(9.5)$ \\
\hline 2 & $\leq 15$ & $21(7.0)$ & $13(6.2)$ \\
\hline$\geq 3$ & $\leq 10$ & $16(5.3)$ & $12(5.7)$ \\
\hline
\end{tabular}

Site

\begin{tabular}{|c|c|c|c|}
\hline Hypopharynx & $\leq 10$ & $\leq 10$ & $\leq 10$ \\
\hline Larynx & 33 (13.5) & 51 (16.9) & $24(11.4)$ \\
\hline Oral cavity & $202(82.8)$ & 237 (78.5) & $176(83.4)$ \\
\hline Oropharynx & $\leq 10$ & $\leq 10$ & $\leq 10$ \\
\hline
\end{tabular}

Extent of disease

$\begin{array}{lcccc}\mathrm{T} 1-2 \mathrm{~N}+ & 16(6.6) & 14(4.6) & 6(2.8) & 0.031 \\ \mathrm{~T} 1-2 \mathrm{~N} 0 & 91(37.3) & 108(35.8) & 58(27.5) & \\ \mathrm{T} 3-4 & 137(56.1) & 180(59.6) & 147(69.7) & \end{array}$

Extent of surgery

\begin{tabular}{ccccc} 
Partial resection & $107(43.9)$ & $122(40.4)$ & $64(30.3)$ & 0.009 \\
Total resection & $137(56.1)$ & $180(59.6)$ & $147(69.7)$ & \\
Neck dissection & & & & \\
No & $149(61.1)$ & $157(52.0)$ & $110(52.1)$ & 0.066 \\
Yes & $95(38.9)$ & $145(48.0)$ & $101(47.9)$ & \\
\hline
\end{tabular}

With or without chemotherapy.

b Score on the Elixhauser Comorbidity Index.

screened, and how often patients have to be screened, we regard outcomes of second primaries as a separate question. Unfortunately, we could not identify second primaries in the same site or patients with second primaries in the same site. That information was not specifically collected in the OCR, and if a patient with a second primary received subsequent treatment, they would have been excluded, just as a patient with recurrence was excluded.

The sixth potential limitation is that the quality of complex electronic data is only as good as the completeness and accuracy of the data input; inevitably, all electronic datasets will have errors. For example, we used the ALR 
TABLE V Distribution of patient and tumour variables by routine frequency of follow-up (RFF) group for patients treated with radiotherapya

\begin{tabular}{|c|c|c|c|c|}
\hline \multirow[t]{2}{*}{ Variable } & \multicolumn{3}{|c|}{ Follow-up group } & \multirow{2}{*}{$\begin{array}{c}p \\
\text { Value }\end{array}$} \\
\hline & Low & Typical & High & \\
\hline Patients $(n)$ & 123 & 1193 & 404 & \\
\hline \multicolumn{5}{|l|}{$\operatorname{Sex}[n(\%)]$} \\
\hline Women & $19(15.4)$ & $229(19.2)$ & $81(20.0)$ & 0.521 \\
\hline Men & $104(84.6)$ & $964(80.8)$ & $323(80.0)$ & \\
\hline \multicolumn{5}{|l|}{ Age group $[n(\%)]$} \\
\hline 35-45 Years & $6(4.9)$ & $72(6.0)$ & $23(5.7)$ & 0.941 \\
\hline 46-55 Years & $43(35.0)$ & $365(30.6)$ & $130(32.2)$ & \\
\hline $56-65$ Years & $45(36.6)$ & $489(41.0)$ & $161(39.9)$ & \\
\hline $66-75$ Years & $29(23.6)$ & $267(22.4)$ & $90(22.3)$ & \\
\hline \multicolumn{5}{|l|}{ Comorbidity group ${ }^{b}[n(\%)]$} \\
\hline 0 & $81(65.9)$ & $840(70.4)$ & $295(73.0)$ & 0.408 \\
\hline 1 & $30(24.4)$ & $220(18.4)$ & $63(15.6)$ & \\
\hline 2 & $\leq 10$ & $61(5.1)$ & $19(4.7)$ & \\
\hline $3+$ & $\leq 10$ & $72(6.0)$ & $27(6.7)$ & \\
\hline \multicolumn{5}{|l|}{ Site $[n(\%)]$} \\
\hline Hypopharynx & $\leq 10$ & $84(7.0)$ & $25(6.2)$ & 0.111 \\
\hline Larynx & $24(19.5)$ & $280(23.5)$ & $117(29.0)$ & \\
\hline Nasopharynx & $\leq 10$ & $79(6.6)$ & $25(6.2)$ & \\
\hline Oral cavity & $35(28.5)$ & $328(27.5)$ & $87(21.5)$ & \\
\hline Oropharynx & $50(40.7)$ & $422(35.4)$ & $150(37.1)$ & \\
\hline \multicolumn{5}{|l|}{ Chemotherapy $[n(\%)]$} \\
\hline No & $37(30.1)$ & $457(38.3)$ & $198(49.0)$ & $<0.001$ \\
\hline Yes & $86(69.9)$ & $736(61.7)$ & $206(51.0)$ & \\
\hline \multicolumn{5}{|l|}{ Neck dissection [n (\%)] } \\
\hline No & $112(91.1)$ & 1069 (89.6) & $348(86.1)$ & 0.116 \\
\hline Yes & $11(8.9)$ & $124(10.4)$ & $56(13.9)$ & \\
\hline Mean treatment duration (days) & $97.34 \pm 27.83$ & $101.78 \pm 33.17$ & $106.62 \pm 37.69$ & 0.01 \\
\hline
\end{tabular}

file to identify the details of RT and chemotherapy, and based on that work, we identified just a few $(\leq 10)$ patients who had both surgery and chemotherapy. We assume that those patients were actually either palliative (and would have been excluded along the way) or that they received chemoradiotherapy. We had no way to confirm either assumption and left those patients in the surgery group. Finally, we report both os and Dss with the understanding that death certificates are not always reliable with respect to cause of death ${ }^{31}$. However, our results for both analyses are consistent.

\section{CONCLUSIONS}

Every day, at every cancer centre, otherwise well patients after curative cancer treatment attend outpatient clinics for routine follow-up with no evidence that the visit or the series of visits planned by the institution improves their chance of survival. This time-honoured physician-driven practice has an emotional and economic cost to many of those patients as well as an economic cost to the health care system. Evidence, such as from a randomized trial, is needed to justify this practice.

\section{ACKNOWLEDGMENTS}

Ethics approval was granted by the Research Ethics Board of Queen's University, Kingston, Ontario, and the Institutional Review Board at Sunnybrook Health Sciences Centre, Toronto, funded in part by a Canadian Cancer Society operating grant (no. 701826).

The analysis was performed at ICES Queens; ICES is funded by an annual grant from the Ontario Ministry of Health and LongTerm Care (монцтс). The project was approved by the Cancer 
Program at ICES. The opinions, results, and conclusions reported in the paper are those of the authors. No endorsement by ICES or the Ontario монцтс is intended or should be inferred.
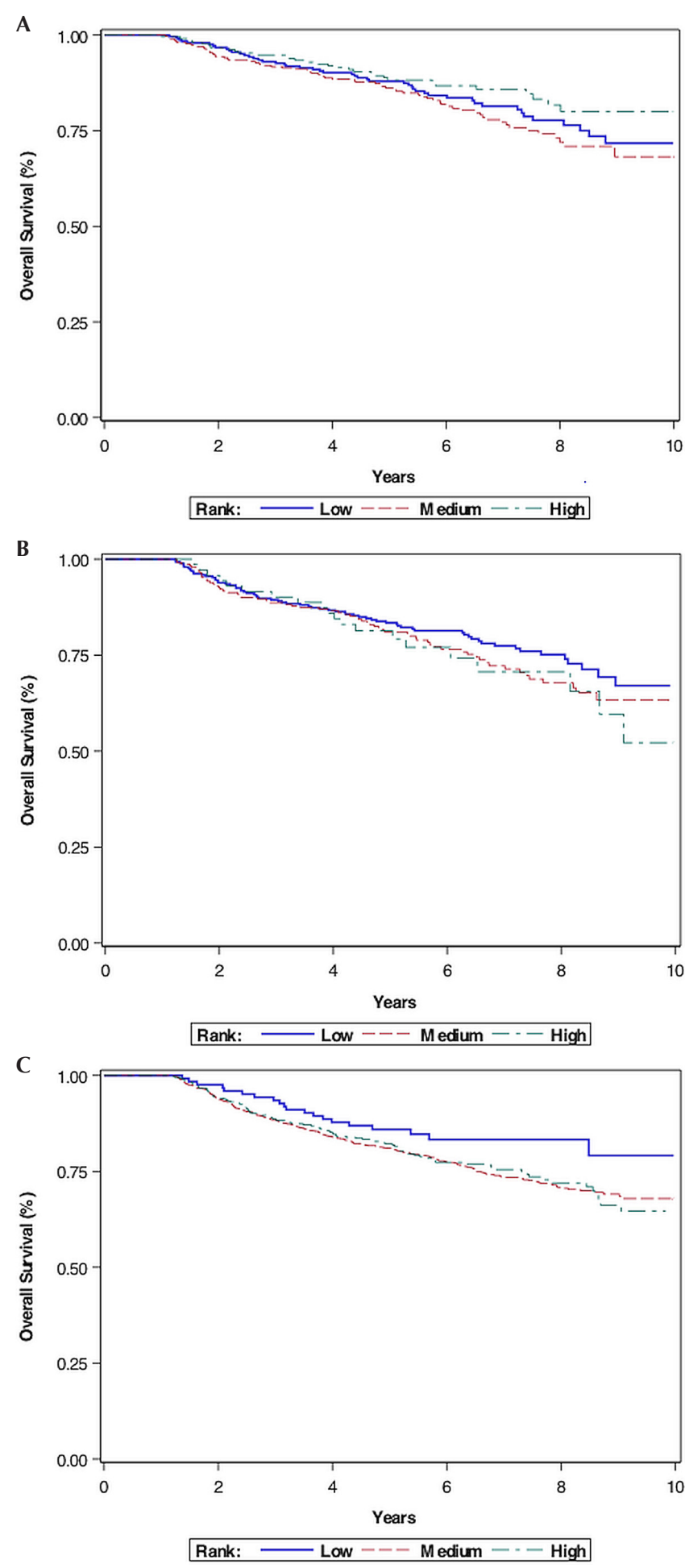

FIGURE 1 (A) Overall survival by routine follow-up frequency for patients treated with surgery. (B) Overall survival by routine follow-up frequency for patients treated with radiotherapy treatment (with or without chemotherapy). (C) Overall survival by routine follow-up frequency for patients receiving combination treatment (surgery and radiotherapy with or without chemotherapy).
Parts of this work are based on data and information provided by Cancer Care Ontario (cco). The opinions, results, views, and conclusions reported in the paper are those of the authors and do not necessarily reflect those of cco. No endorsement by cco is intended or should be inferred.

Parts of this work are based on data and information compiled and provided by the Canadian Institute for Health Information (CIHI). The analyses, conclusions, opinions, and statements expressed herein are those of the authors and not necessarily those of CIHI.

A synopsis of this work was presented at the Annual Scientific Meeting of the Canadian Otolaryngology Society; Quebec City, Quebec; 16-19 June 2018.

\section{CONFLICT OF INTEREST DISCLOSURES}

We have read and understood Current Oncology's policy on disclosing conflicts of interest, and we declare that we have none.

TABLE VI Hazard ratios (HRs) from the multiple variable analysis models for overall survival in the patients undergoing surgery

\begin{tabular}{|c|c|c|}
\hline Variable & HR & $95 \% \mathrm{Cl}$ \\
\hline \multicolumn{3}{|l|}{ Sex } \\
\hline Women & 1.00 & \\
\hline Men & 1.287 & 0.897 to 1.848 \\
\hline \multicolumn{3}{|l|}{ Age group } \\
\hline $35-55$ Years & 1.00 & \\
\hline 46-55 Years & 0.903 & 0.402 to 2.026 \\
\hline 56-65 Years & 1.181 & 0.550 to 2.534 \\
\hline 66-75 Years & 1.599 & 0.753 to 3.392 \\
\hline
\end{tabular}

Comorbidity group ${ }^{\mathrm{a}}$

$\begin{array}{lll}0 & 1.00 & \\ 1 & 1.436 & 0.926 \text { to } 2.227 \\ 2 & 1.937 & 1.093 \text { to } 3.432 \\ 3+ & 2.916 & 1.552 \text { to } 5.481\end{array}$

$\begin{array}{lcc}\text { Site } & & \\ \text { Oral cavity } & 1.00 & \\ \text { Hypopharynx } & 5.476 & 3.134 \text { to } 9.567 \\ \text { Larynx } & 1.339 & 0.812 \text { to } 2.208 \\ \text { Oropharynx }^{b} & 0.000 & 0.000\end{array}$

Extent of disease

Early $\quad 1.00$

$\begin{array}{lll}\text { Early } \mathrm{N}+ & 1.380 & 0.642 \text { to } 2.969 \\ \text { Advanced } & 1.495 & 0.988 \text { to } 2.262\end{array}$

\begin{tabular}{lcc} 
RFF group & & \\
Low & 1.346 & 0.848 to 2.136 \\
Typical & 1.459 & 0.943 to 2.255 \\
High & 1.00 & \\
\hline
\end{tabular}

a Score on the Elixhauser Comorbidity Index.

b Insufficient cases.

$\mathrm{Cl}=$ confidence interval. 
TABLE VII Hazard ratios (HRs) from the multivariable analysis models for overall survival and disease-specific survival by routine frequency of follow-up (RFF) group in each of the treatment groups

\begin{tabular}{|c|c|c|c|c|c|}
\hline \multirow{2}{*}{$\begin{array}{l}\text { Survival } \\
\text { variable }\end{array}$} & \multirow[t]{2}{*}{ Treatment } & \multirow{2}{*}{$\begin{array}{c}\text { RFF } \\
\text { group }\end{array}$} & \multirow[t]{2}{*}{ HR } & \multicolumn{2}{|c|}{$95 \% \mathrm{CL}$} \\
\hline & & & & Upper & Lower \\
\hline \multicolumn{6}{|l|}{ Overall } \\
\hline \multicolumn{6}{|c|}{ Surgery } \\
\hline & & Low & 1.346 & 0.848 & 2.136 \\
\hline & & Typical & 1.459 & 0.943 & 2.255 \\
\hline & & High & 1.00 & & \\
\hline \multicolumn{6}{|c|}{ Radiotherapy } \\
\hline & & Low & 0.659 & 0.407 & 1.066 \\
\hline & & Typical & 0.998 & 0.795 & 1.253 \\
\hline & & High & 1.00 & & \\
\hline \multicolumn{6}{|c|}{ Combined } \\
\hline & & Low & 1.002 & 0.595 & 1.688 \\
\hline & & Typical & 1.061 & 0.632 & 1.782 \\
\hline & & High & 1.00 & & \\
\hline \multicolumn{6}{|c|}{ Disease-specific } \\
\hline \multicolumn{6}{|c|}{ Surgery } \\
\hline & & Low & 0.828 & 0.270 & 2.537 \\
\hline & & Typical & 1.216 & 0.459 & 3.226 \\
\hline & & High & 1.00 & & \\
\hline \multicolumn{6}{|c|}{ Radiotherapy } \\
\hline & & Low & 0.764 & 0.355 & 1.647 \\
\hline & & Typical & 0.896 & 0.614 & 1.307 \\
\hline & & High & 1.00 & & \\
\hline \multicolumn{6}{|c|}{ Combined } \\
\hline & & Low & 2.244 & 0.762 & 6.607 \\
\hline & & Typical & 1.695 & 0.564 & 5.097 \\
\hline & & High & 1.00 & & \\
\hline
\end{tabular}

$\mathrm{CL}=$ confidence limits.

\section{AUTHOR AFFILIATIONS}

*Department of Otolaryngology and Division of Cancer Care and Epidemiology of the Queen's Cancer Research Institute, 'Department of Oncology, Division of Radiation Oncology, and ${ }^{\ddagger}$ ICES Queen’s, Queen's University, Kingston, ON; ${ }^{\S}$ Clinical Research Centre, Dalhousie University, Halifax, NS.

\section{REFERENCES}

1. Grunfeld E. Looking beyond survival: how are we looking at survivorship? J Clin Oncol 2006;24:5166-9.

2. British Association of Head and Neck Oncologists. Practice care guidance for clinicians participating in the management of head and neck cancer patients in the UK. Drawn up by a Consensus Group of Practising Clinicians. Eur J Surg Oncol 2001;27(suppl A):S1-17.

3. BC Cancer. 7. Follow-up: Squamous Cell Carcinoma [Web page, subtopic of Head and Neck Cancer for health professionals]. Vancouver, BC: BC Cancer; 2003. [Available at: http://www.bccancer.bc.ca/health-professionals/clinicalresources/cancer-management-guidelines/head-neck/ head-neck\#follow-up; cited 1 August 2019]

4. Cohen EE, LaMonte SJ, Erb NL, et al. American Cancer Society head and neck cancer survivorship care guideline. $C A$ Cancer J Clin 2016;66:203-39. [Erratum in: CA Cancer J Clin 2016;66:351]

5. Gilbert R, Devries-Aboud M, Winquist E, Waldron J, McQuestion M on behalf of the Head and Neck Disease Site Group. The Management of Head and Neck Cancer in Ontario [archived]. Evidence Based Series 5-3. Toronto, ON: Cancer Care Ontario; 2009. [Available online at: https://www.cancercareontario. ca/sites/ccocancercare/files/guidelines/full/pebc5-3f.pdf; cited 12 August 2019]

6. Roman BR, Goldenberg D, Givi B on behalf of the Education Committee of American Head and Neck Society (AHNS). AHNS series: Do you know your guidelines? Guideline recommended follow-up and surveillance of head and neck cancer survivors. Head Neck 2016;38:168-74.

7. Cooney TR, Poulsen MG. Is routine follow-up useful after combined modality therapy for advanced head and neck cancer? Arch Otolaryngol Head Neck Surg 1999;125:379-82.

8. Francis DO, Yueh B, Weymuller EA Jr, Merati AL. Impact of surveillance on survival after laryngeal cancer in the Medicare population. Laryngoscope 2009;119:2337-44.

9. Haas I, Hauser U, Ganzer U. The dilemma of follow-up in head and neck cancer patients. Eur Arch Otorhinolaryngol 2001;258:177-83.

10. Kazi R, Manikanthan K, Pathak KA, Dwivedi RC. Head and neck squamous cell cancers: need for an organised time-bound surveillance plan. Eur Arch Otorhinolaryngol 2010;267:1969-71.

11. Manikantan K, Khode S, Dwivedi RC, et al. Making sense of post-treatment surveillance in head and neck cancer: when and what of follow-up. Cancer Treat Rev 2009;35:744-53.

12. Morton RP, Hay KD, Macann A. On completion of curative treatment of head and neck cancer: why follow up? Curr Opin Otolaryngol Head Neck Surg 2004;12:142-6.

13. Ritoe SC, Krabbe PF, Kaanders JH, van den Hoogen FJ, Verbeek AL, Marres HA. Value of routine follow-up for patients cured of laryngeal carcinoma. Cancer 2004;101:1382-9.

14. Schwartz DL, Barker J Jr, Chansky K, et al. Postradiotherapy surveillance practice for head and neck squamous cell carcinoma-too much for too little? Head Neck 2003;25:990-9.

15. Boysen M, Lövdal O, Tausjö J, Winther F. The value of routine follow-up in patients treated for squamous cell carcinoma of the head and neck. Eur J Cancer 1992;28:426-30.

16. Flynn C, Khaouam N, Gardner S, et al. The value of periodic follow-up in the detection of recurrences after radical treatment in locally advanced head and neck cancer. Clin Oncol (R Coll Radiol) 2010;22:868-73.

17. Lester SE, Wight RG. "When will I see you again?" Using local recurrence data to develop a regimen for routine surveillance in post treatment head and neck cancer patients. Clin Otolaryngol 2009;34:546-51.

18. Cooper JS, Porter K, Mullin K, et al. National Cancer Database report on cancer of the head and neck: 10 year update. Head Neck 2009;31:748-58.

19. Gupta B, Maio Q, Kong W, Peng P, Mioa G, Mackillop WJ. Temporal trends in incidence and survival for cancers of the upper aerodigestive tract in Ontario and the United States. Int J Cancer 2009;125:2159-65.

20. Wennberg JE. Dealing with medical practice variation: a proposal for action. Health Aff (Millwood) 1984;3:6-32.

21. Brennan KE, Hall SF, Owen TE, Griffiths RJ, Peng Y. Variation in routine follow-up care after curative treatment of head and neck cancer: a population-based study in Ontario, Canada. Curr Oncol 2018;25:e120-31. 
22. Austin PC, Stanbrook MB, Anderson GM, Newman A, Gershon AS. Comparative ability of comorbidity classification methods for administrative data to predict outcomes in patients with chronic obstructive pulmonary disease. Ann Epidemiol 2012;22:881-7.

23. Elixhauser A, Steiner C, Harris DR, Coffey RM. Comorbidity measures for use in administrative data. Med Care 1998;36:8-27.

24. Quan H, Sundararajan V, Halfon P, et al. Coding algorithms for defining comorbidities in ICD-9-CM and ICD-10 administrative data. Med Care 2005;43:1130-9.

25. Brewer N, Borman B, Sarfati D, et al. Does comorbidity explain the ethnic inequalities in cervical cancer survival in New Zealand? BMC Cancer 2011;11:132.

26. Hall SF, Griffiths RJ. Evaluation of treatment outcomes in patients with supraglottic laryngeal cancer in Ontario, Canada: a population-based study. Head Neck 2018;40:1024-33.
27. De Felice F, Musio D, Tombolini V. Follow-up in head and neck cancer: a management dilemma. Adv Otolaryngol 2015;:1-4.

28. Paniello RC, Virgo KS, Johnson MH, Clemente MF, Johnson FE. Practice patterns and clinical guidelines for posttreatment follow-up of head and neck cancers. Arch Otolaryngol Head Neck Surg 1999;125:309-13.

29. Nekhlyudov L, Lacchetti C, Davis NB, et al. Head and neck cancer survivorship care guideline: American Society of Clinical Oncology clinical practice guideline endorsement of the American Cancer Society guideline. J Clin Oncol 2017;35:1606-21.

30. Brennan KF, Hall SE, Yoo J, et al. Routine follow-up care after curative treatment of head and neck cancer: a survey of patients' needs and preferences for health care services. Eur J Cancer Care (Engl) 2019;28:e12993.

31. Hall S, Schulze K, Groome P, Mackillop W, Holowaty E. Using cancer registry data for survival studies: the example of the Ontario Cancer Registry. J Clin Epidemiol 2006;59:67-76. 